\title{
The use of infliximab for treatment of hospitalized patients with acute severe ulcerative colitis
}

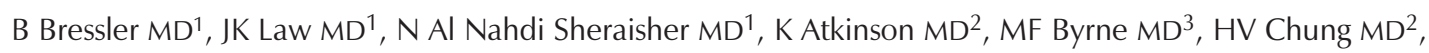 \\ $M$ Fishman $M D^{4}$, N Partovi MD, ${ }^{3}$ D Pearson $M D^{5}, R$ Penner $M D^{6}$, RA Enns $M D^{1}$
}

B Bressler, JK Law, N Al Nahdi Sheraisher, et al. The use of infliximab for treatment of hospitalized patients with acute severe ulcerative colitis. Can J Gastroenterol 2008;22(11):937-940.

BACKGROUND/AIM: The use of infliximab in severe ulcerative colitis (UC) is established; however, its role in severe acute UC requires clarification. The present multicentre case series evaluated infliximab in hospitalized patients with steroid-refractory severe UC. METHODS: Patients from six hospitals were retrospectively evaluated. Data collection included demographics, duration of disease and previous treatments. The primary end point was response to in-hospital infliximab; defined as discharge without colectomy.

RESULTS: Twenty-one patients (median age 26 years) were admitted between May 2006 and May 2008 with severe UC requiring intravenous steroids and given infliximab (median time to infusion eight days). Sixteen $(76 \%)$ patients were discharged home without colectomy; three of these underwent colectomy at a later date. Of the remaining 13 patients $(62 \%)$, all but two did not require further courses of steroids; six patients had infliximab as a bridge to azathioprine and seven patients were maintained on regular infliximab. Five patients required in-hospital colectomy after the initial infliximab.

CONCLUSIONS: In this real-life experience of infliximab in patients with steroid-refractory severe UC, infliximab appears to be a viable rescue therapy. The majority of patients were discharged without surgery and $62 \%$ maintained response either as a bridge to azathioprine or maintenance infliximab.

Key Words: Infliximab, Medical refractory, Severe ulcerative colitis

Infliximab, an antitumour necrosis factor-alpha monoclonal antibody, is the first biologic agent to receive approval for use in treatment of patients with ulcerative colitis (UC) by Health Canada (1). The evidence supporting its use for inducing clinical response and remission in steroid-refractory severe UC is mixed. Two initial studies suggested little benefit of infliximab in this clinical context. In 2001, Sands et al (2) performed a study with 11 patients comparing various doses of infliximab with placebo in patients with severe disease refractory to intravenous (IV) corticosteroids after at least five days. Patients received one infusion and were evaluated at weeks 2 and 12 . At week 2, there was a response in some patients to various doses of infliximab (two of three patients in the $5 \mathrm{mg} / \mathrm{kg}$ subgroup, one of three patients in the $10 \mathrm{mg} / \mathrm{kg}$ subgroup, and one of

\section{Le recours à l'infliximab dans le traitement de patients hospitalisés atteints d'une grave colite ulcéreuse aiguë}

HISTORIQUE ET OBJECTIF : Le recours à l'infliximab en cas de colite ulcéreuse (CU) grave est établi. Cependant, son rôle n'est pas clair en présence d'une grave $\mathrm{CU}$ aiguë. La présente série de cas multicentriques a permis d'évaluer l'infliximab chez des patients hospitalisés atteints d'une grave CU réfractaire aux stéroïdes.

MÉTHODOLOGIE : Des patients de six hôpitaux ont fait l'objet d'une évaluation rétrospective. La collecte de données a inclus les données démographiques, la durée de la maladie et les traitements antérieurs. Le paramètre ultime primaire était une réponse à l'infliximab en milieu hospitalier, définie par un congé sans colectomie.

RÉSULTATS : Vingt et un patients d'un âge médian de 26 ans ont été hospitalisés entre mai 2006 et mai 2008 en raison d'une CU grave exigeant l'administration de stéroïdes par voie intraveineuse et ont reçu de l'infliximab (délai médian de huit jours avant l'infusion). Seize patients (76\%) ont obtenu leur congé sans subir de colectomie, mais trois l'ont subie plus tard. Chez les 13 patients restants (62\%), tous sauf deux n'ont pas eu besoin d'autres stéroïdes. Six patients ont pris de l'infliximab en attendant de passer à l'azathioprine et sept ont continué de prendre de l'infliximab ordinaire. Cinq patients ont dû être hospitalisés pour subir une colectomie après le traitement initial à l'infliximab.

CONCLUSIONS : Dans le cadre de cette expérience réelle d'administration d'infliximab chez des patients atteints d'une grave CU réfractaire aux stéroïdes, l'infliximab semble constituer une thérapie de sauvetage viable. La majorité des patients ont obtenu leur congé sans se faire opérer et $62 \%$ ont maintenu leur réponse avant de prendre de l'azathioprine ou de l'infliximab d'entretien.

two patients in the $20 \mathrm{mg} / \mathrm{kg}$ subgroup), compared with no patients responding to placebo. At week 12 , only the two patients in the $20 \mathrm{mg} / \mathrm{kg}$ subgroup had a durable response. A study performed by Probert et al (3) involved 43 patients with acute moderate-to-severe UC who were refractory to seven days of prednisolone $(30 \mathrm{mg} / \mathrm{kg})$. Twenty-three patients received infliximab $(5 \mathrm{mg} / \mathrm{kg})$, and 20 received placebo at days 0 and 14 . A clinical response at week 6 was the primary end point. In the infliximab group, nine of 23 patients met this end point compared with six of 20 patients in the placebo group. Both studies questioned the role of infliximab in patients with acute steroid-refractory UC. A more recent study, published in 2005 by Jarnerot et al (4), led to a different conclusion regarding the efficacy of infliximab in this clinical context. Patients

Departments of Medicine and Laboratory Sciences, St Paul's Hospital, University of British Columbia, Vancouver; ${ }^{2}$ Royal Columbian Hospital,

New Westminster; ${ }^{2}$ Vancouver General Hospital, Vancouver; ${ }^{3}$ Richmond General Hospital, Richmond; ${ }^{4}$ Victoria and Royal Jubilee Hospital,

Victoria; ${ }^{6}$ Kelowna General Hospital, Kelowna, British Columbia.

Correspondence: Dr Brian Bressler, 770-1190 Hornby Street Vancouver, British Columbia V6Z 2K5. Telephone 604-688-6332,

fax604-689-2004,e-mail brian_bressler@hotmail.com

Received for publication July 2, 2008. Accepted August 26, 2008 


\section{TABLE 1}

\section{Patient demographics}

\begin{tabular}{|c|c|c|}
\hline Demographic & $\begin{array}{c}\text { Responders } \\
(n=16)\end{array}$ & $\begin{array}{l}\text { Nonresponders } \\
\quad(n=5)\end{array}$ \\
\hline Age, years & $30.6(18.1-70.5)$ & $21.3(19.3-32.6)$ \\
\hline Males, n (\%) & $12(75.0)$ & $3(60.0)$ \\
\hline $\begin{array}{l}\text { Duration of disease, } \\
\text { years }\end{array}$ & $2.89(0.45-18.4)$ & $1.89(0.26-12.4)$ \\
\hline \multicolumn{3}{|l|}{ Extent of disease, n (\%) } \\
\hline Left-sided colitis & $2(12.5)$ & $0(0)$ \\
\hline Pancolitis & $13(81.3)$ & $5(100)$ \\
\hline Unknown & $1(6.3)$ & - \\
\hline \multicolumn{3}{|l|}{ Past medication use, $\mathrm{n}(\%)$} \\
\hline Steroids & $13(81.3)$ & $4(80)$ \\
\hline 5-ASA products & $13(81.3)$ & $4(80)$ \\
\hline Azathioprine/6-MP & $6(37.5)$ & $3(60)$ \\
\hline Cyclosporine & $0(0)$ & $2(40)$ \\
\hline $\begin{array}{l}\text { Hospital length of stay, } \\
\text { days }\end{array}$ & $13(6-37)$ & $46(15-66)$ \\
\hline Hemoglobin, g/L & $106.5(80.0-136)$ & $28(85-157)$ \\
\hline $\begin{array}{l}\text { White blood cell count, } \\
\times 10^{3} / \mu \mathrm{L}\end{array}$ & $12.7(6.0-17.7)$ & $9.8(6.7-18.4)$ \\
\hline Albumin, g/L & $31.5(17-40)$ & $20(13-29)$ \\
\hline $\begin{array}{l}\text { C-reactive protein, } \\
\mathrm{mg} / \mathrm{L}\end{array}$ & $54.5(0.6-156)$ & $35.8(11.8-195)$ \\
\hline $\begin{array}{l}\text { Days of intravenous steroid } \\
\text { infusion before infliximab, }\end{array}$ & $7(3-20)$ & $11(6-19)$ \\
\hline $\begin{array}{l}\text { Days from infliximab infusion } \\
\text { to surgery }\end{array}$ & $\begin{array}{l}46(12-63) \\
\quad(n=3 \text { patients })\end{array}$ & $\begin{array}{l}9(2-42) \\
\quad(n=5 \text { patients })\end{array}$ \\
\hline
\end{tabular}

All values presented as mean (range) unless specified otherwise. 5-ASA 5-aminosalicylic acid; 6-MP 6-Mercaptopurine

with moderate-to-severe UC not responding adequately to intravenous steroids within eight days of therapy were randomly assigned to receive one dose of infliximab $(5 \mathrm{mg} / \mathrm{kg})(\mathrm{n}=24)$ or placebo $(n=21)$. Their primary end point was either colectomy or death at 90 days. Seven of 24 patients in the infliximab group compared with 14 of 21 patients in the placebo group had a colectomy at 90 days $(\mathrm{P}=0.017)$. At 90 days, clinical remission rates and endoscopic remission rates were not statistically different between the two groups.

In a more recent Italian multicentre study by Kohn et al (5), 83 patients with severe UC received infliximab at the discretion of the investigator, generating promising results. Only $15 \%$ of patients required colectomy within two months and only one serious complication (Legionella pneumonia death) was noted during that time frame. Over a period of 23 months, $70 \%$ of patients avoided colectomy. In a separate, more recent study (6) in patients with steroid-dependant and refractory UC, 53\% remained colectomy-free at 12 months following infusions of infliximab.

Although these data are limited, the use of infliximab has quickly become commonplace for the treatment of hospitalized patients in North America with acute severe UC not responding to intravenous steroids. Because of the potential safety concerns and cost of infliximab treatment and other available treatment options such as colectomy or cyclosporine, it is necessary to evaluate the experience of this medication outside the clinical trial context. The present study evaluated the impact of infliximab in the treatment of hospitalized patients with acute severe UC.

\section{METHODS}

A retrospective cohort study of patients with UC who received infliximab while admitted to one of six hospitals in British Columbia from May 2006 to May 2008 was performed. Patients were identified by gastroenterologists at each hospital and crossreferenced with the pharmacy department at every institution to ensure completeness. Only patients with a clear diagnosis of UC who were prescribed infliximab in hospital were included in the cohort. A chart review was performed collecting demographic data (age, sex, smoking, pregnancy status) and disease-related data (age at diagnosis, length of time with UC, disease extent, symptoms requiring hospitalization, previous medication used for UC, current medication used for UC before hospitalization and medication used in hospital for UC before initiating infliximab). If endoscopy was performed, data regarding disease extent and severity were collected. Laboratory values before initiating infliximab were collected including complete blood count, C-reactive protein, erythrocyte sedimentation rate, total cholesterol and albumin.

In-hospital response to infliximab was the primary end point of the present study. This response was defined as avoiding colectomy during hospitalization, with the patient being discharged home. Secondary end points were length of hospital stay, time to surgery (if necessary) and any adverse events in hospital.

\section{RESULTS}

Twenty-one patients with acute severe UC (none with isolated proctitis) requiring hospital admission failing IV steroids were treated with infliximab from May 2006 to May 2008. The median number of days of follow-up of the present cohort was 155 days from the date of hospital admission (range 13 to 494 days). The cohort consisted of 15 men $(71.4 \%)$, median age 26 years (range 18 to 71 years) (Table 1 ). The median duration of disease was 2.5 years (range 0.4 to 18 years). Seven patients $(33 \%)$ were steroid dependent before admission. Nine patients were on maintenance azathioprine/6-mercaptopurine (6-MP), and two patients were on maintenance oral cyclosporine before hospital admission. Seventeen patients $(86 \%)$ in the cohort had pancolitis, two patients had left-sided colitis and the extent of disease in the other patients was unknown.

All patients were initially treated with IV steroids during hospital admission. Based on the clinical judgment of the treating gastroenterologists, all patients in the cohort failed IV steroids and required step-up therapy to more aggressive medical management. All patients subsequently received $5 \mathrm{mg} / \mathrm{kg}$ of infliximab. The median number of days on IV steroids in hospital before infliximab initiation was eight days (range three to 26 days). Sixteen patients (76\%) responded to infliximab (Figure 1) and were discharged without colectomy with plans for all to have subsequent infusions at two and six weeks following their initial infusion. The median length of stay in hospital for the infliximab responders was 13 days (range six to 37 days). Five patients required a colectomy during the same hospital admission after failing a single dose of infliximab (Figure 1). The presenting laboratory values for the patients in 
the responding and nonresponding groups are shown in Table 1. No significant difference exists between these two groups' values except for a lower albumin in the nonresponders compared with the responders.

Seven of the 16 patients who responded to infliximab were then started on azathioprine or 6-MP. Six of the responders immediately received infliximab $5 \mathrm{mg} / \mathrm{kg}$ every eight weeks as maintenance therapy. Within four months of hospital discharge, 11 of 16 responders were in steroid-free clinical remission; two patients required subsequent courses of oral steroids for flares. Three patients who initially responded to infliximab eventually required a colectomy at a median duration from initial hospital discharge of 44 days (range eight to 59 days). One of those patients developed a colonic perforation 63 days after infliximab infusion.

Five patients did not respond to infliximab and required a colectomy during the same hospital admission. Two patients had infectious complications noted. One patient developed localized herpes zoster after receiving infliximab, while another patient developed severe community-acquired pneumonia requiring hospitalization. Both patients were on concomitant azathioprine therapy in addition to regular infliximab; the former patient discontinued infliximab while the latter stopped azathioprine. Both infectious complications resolved with medical therapy with no sequalae.

\section{DISCUSSION}

Since the randomized controlled clinical trial by Jarnerot et al (4), comparing infliximab with placebo, the enthusiasm for using infliximab in hospitalized patients with steroid-refractory acute UC has grown. Over the course of 18 months, in six hospitals in British Columbia, 21 patients were identified as having received one dose of infliximab as rescue therapy for steroid-refractory acute UC. Three-quarters of these patients responded to infliximab, meaning they avoided colectomy during their hospitalization and were discharged. Of those who initially responded, 11 of 16 (69\%) had a durable response leading to a steroid-free clinical remission within four months of hospital discharge. The only difference between responders and nonresponders was a lower serum albumin level in the nonresponder group. Interestingly, this was found in a retrospective study in Scotland (7) of 39 patients with severe UC treated with infliximab, in which a finding of low serum albumin was also a predictor of poor response.

To date, the only other acceptable rescue therapy for patients with UC refractory to IV steroids is cyclosporine. At many centres in North America, this therapy has fallen out of favour because of its serious adverse event profile (8-17), poor long-term efficacy $(11,18-22)$ and the intense clinical and biochemical monitoring required while patients are taking this medication. Although there are no direct comparisons with cyclosporine, the safety profile of infliximab appears to be superior to that of cyclosporine (4). No significant adverse events were seen in our cohort of patients who responded to infliximab except for one patient who developed a colonic perforation 63 days after infliximab infusion, and one patient who required hospitalization for community-acquired pneumonia. A complete understanding of the adverse event profile of infliximab when used in this context is required because this treatment strategy is relatively new and further data are necessary. Furthermore, comments on the long-term durability of

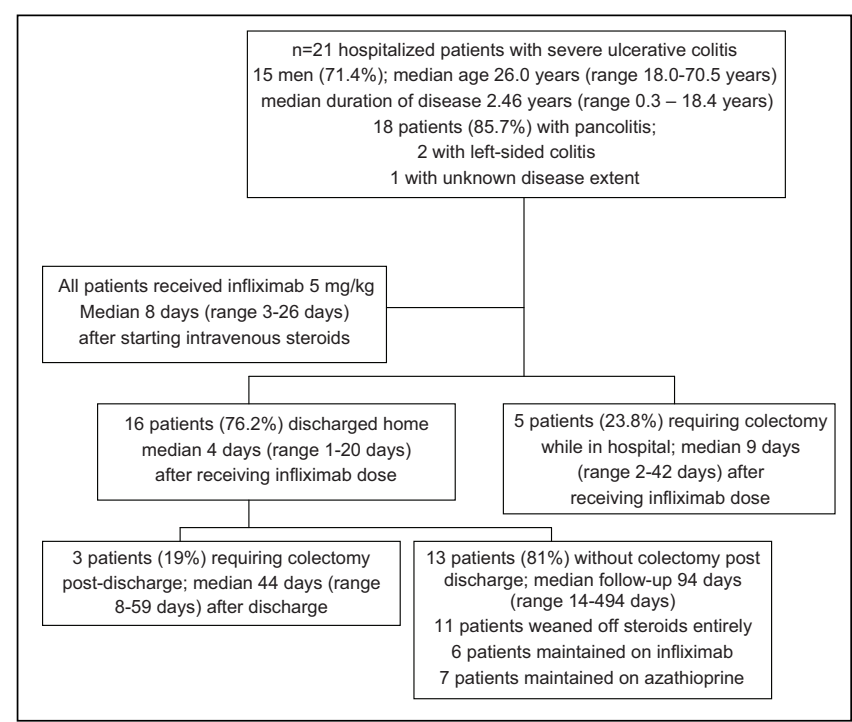

Figure 1) Flow diagram of the treatment course in hospitalized patients with severe ulcerative colitis

infliximab tend to be speculative. In our cohort, one-third of patients (eight of 21) eventually required a colectomy for treatment of their active UC, the majority of whom (63\%) required an operation during their initial admission.

At the time of the present study in British Columbia, infliximab was not reimbursed by the provincial formulary for treatment of UC. The only way a patient could have received infliximab after hospital discharge would have been through a third-party insurer or personal financing. Because of this limitation, only six patients received maintenance infusions. Continuing infliximab with an appropriate induction regimen followed by maintenance infusions every eight weeks for patients requiring this medication in hospital may be the optimal way to maintain long-term remission. This is probably most relevant in patients requiring infliximab after being on azathioprine/6-MP before hospitalization for a severe flare of their UC.

In Canada, gastroenterologists have been using infliximab for the treatment of Crohn's disease for approximately eight years. Because of this experience, and the minimal amount of patient monitoring required postinfusion, infliximab is considered by many to be more convenient to use (as opposed to cyclosporine) in patients with UC failing IV steroids.

Many questions remain regarding the use of infliximab for acute severe UC. We believe the timing of this intervention may be a critical predictor of a positive response. In our cohort, the median time to receiving infliximab after initiating IV steroids was eight days. The delay for infusion was partly related to the logistics of payment for the drug in our setting. Clinical parameters are available to predict the need for colectomy in patients receiving IV steroids as early as three days into therapy (23-26). Using infliximab earlier during a hospital admission, once it is known that IV steroids will not likely prevent the need for colectomy, might improve outcomes and reduce costs by shortening the length of hospital stay. To accomplish earlier administration of infliximab, the necessary precautionary measures such as a tuberculosis skin test and chest $\mathrm{x}$-ray should be completed as soon as possible after admission so as to not delay commencement of infliximab therapy. Hepatitis B status was not routinely evaluated at the time of the present 
study but likely should also be included in the screening before infliximab administration. The optimal management after hospital discharge in patients responding to infliximab as a rescue therapy is also unknown. Most investigators suspect that those patients that have required such therapy in hospital will require a form of maintenance therapy. Whether infliximab can be used similarly to cyclosporine as a bridge to azathioprine/6-MP therapy, or whether it is necessary to continue infliximab as a maintenance medication is unknown. The benefit of using concomitant infliximab and azathioprine/6-MP therapy may be most appropriate. However, data from the Active ulcerative Colitis Trials (ACT) 1 and 2 (27), do not suggest concomitant immunosuppressive therapy is necessary when using infliximab as maintenance therapy. This combination therapy

\section{REFERENCES}

1. Health Flash: A quarterly publication: New Drugs and Indications (DEC conference proceedings). 2006;4:1-4.

2. Sands BE, Tremaine WJ, Sandborn WJ, et al. Infliximab in the treatment of severe, steroid-refractory ulcerative colitis: A pilot study. Inflamm Bowel Dis 2001;7:83-8.

3. Probert CS, Hearing SD, Schreiber S, et al. A. Infliximab in moderately severe glucocorticoid resistant ulcerative colitis: A randomised controlled trial. Gut 2003;52:998-1002.

4. Jarnerot $G$, Hertervig E, Friis-Liby I, et al. Infliximab as rescue therapy in severe to moderately severe ulcerative colitis: A randomized, placebo-controlled study. Gastroenterology 2005;128:1805-11.

5. Kohn A, Daperno M, Armuzzi A, et al. Infliximab in severe ulcerative colitis: Short-term results of different infusion regimens and long-term follow-up. Aliment Pharmacol Ther 2007;26:747-56.

6. Willert RP, Lawrance IC. Use of infliximab in the prevention and delay of colectomy in severe steroid dependant and refractory ulcerative colitis. World J Gastroenterol 2008;14:2544-9.

7. Lees CW, Heys D, Ho GT, et al. A retrospective analysis of the efficacy and safety of infliximab as rescue therapy in acute severe ulcerative colitis. Aliment Pharmacol Ther 2007;26 411-19.

8. Minami M, Ohta M, Ohkura T, et al. Cytomegalovirus infection in severe ulcerative colitis patients undergoing continuous intravenous cyclosporine treatment in Japan. World J Gastroenterol 2007;13:754-60.

9. Shibahara T, Miyazaki K, Sato D, et al. Rectal malignant lymphoma complicating ulcerative colitis treated with long-term cyclosporine A. J.Gastroenterol.Hepatol. 2006;21:336-8.

10. Hibi K, Kusugami K, Ina K, et al. A. Disseminated intravascular coagulation associated with systemic cytomegalovirus infection during cyclosporine therapy for ulcerative colitis: Report of a case. Dis Colon Rectum 2006;49:127-31.

11. Poritz LS, Rowe WA, Swenson BR, Hollenbeak CS, Koltun WA. Intravenous cyclosporine for the treatment of severe steroid refractory ulcerative colitis: What is the cost? Dis Colon Rectum 2005;48:1685-90.

12. Al-Shekhlee A, Oghlakian G, Katirji B. A case of cyclosporineinduced dural sinus thrombosis. J Thromb Haemost 2005;3:1327-8.

13. Sood A, Midha V, Sood N. Reversible posterior leukoencephalopathy due to oral cyclosporine in severe ulcerative colitis. Indian J Gastroenterol 2003;22:233-4. also likely leads to an increased risk of opportunistic infections (28). Until studies demonstrate a clear benefit of using infliximab with azathioprine/6-MP, we would caution against this approach. The present study was not, however, designed to assess this issue and longer-term data are clearly required.

New treatments for new indications are necessary to study outside clinical trials. A strength of the present study is the varied clinical environment in which the cohort of patients were treated. In the present multicentre study of 21 patients, the response rate of infliximab as a rescue therapy in patients failing IV steroids was $76 \%$, allowing for a hospital discharge without colectomy. We conclude that infliximab is a safe and effective strategy to consider in hospitalized patients with severe UC.

14. McCormack G, McCormick PA, Hyland JM, O’Donoghue DP. Cyclosporin therapy in severe ulcerative colitis: Is it worth the effort? Dis Colon Rectum 2002;45:200-5.

15. Caroli A, Fregonese D, Di FG, D'Inca R. Aspergillus fumigatus pneumonia during cyclosporine treatment for ulcerative colitis. Am J Gastroenterol 2000;95:3016-7.

16. Haslam N, Hearing SD, Probert CS. Audit of cyclosporin use in inflammatory bowel disease: Limited benefits, numerous side-effects. Eur J Gastroenterol Hepatol 2000;12:657-60.

17. Hinterreiter M, Stadler B, Knoflach P. Recurrent septicemia with lethal outcome during and after cyclosporine therapy in severe ulcerative colitis. Acta Med Austriaca 2000;27:91-3.

18. Moskovitz DN, Van AG, Maenhout B, et al. Incidence of colectomy during long-term follow-up after cyclosporine-induced remission of severe ulcerative colitis. Clin Gastroenterol Hepatol 2006;4:760-5.

19. Pham CQ, Efros CB, Berardi RR. Cyclosporine for severe ulcerative colitis. Ann Pharmacother 2006;40:96-101.

20. Garcia-Lopez S, Gomollon-Garcia F, Perez-Gisbert J. Cyclosporine in the treatment of severe attack of ulcerative colitis: A systematic review. Gastroenterol Hepatol 2005;28:607-14.

21. Arts J, D'Haens G, Zeegers M, et al. Long-term outcome of treatment with intravenous cyclosporin in patients with severe ulcerative colitis. Inflamm Bowel Dis 2004;10:73-8.

22. Sandborn WJ. Cyclosporine in ulcerative colitis: State of the art. Acta Gastroenterol Belg 2001;64:201-4.

23. Campbell S, Travis S, Jewell D. Ciclosporin use in acute ulcerative colitis: A long-term experience. Eur J Gastroenterol Hepatol 2005; 17:79-84.

24. Hyde GM, Jewell DP. Review article: The management of severe ulcerative colitis. Aliment Pharmacol Ther 1997;11:419-24.

25. Travis SP, Farrant JM, Ricketts C, et al. Predicting outcome in severe ulcerative colitis. Gut 1996;38:905-10.

26. Dalton HR, Jewell DP. The management of acute severe ulcerative colitis. Ann Med 1991;23:389-91.

27. Rutgeerts P, Sandborn WJ, Feagan BG, et al. Infliximab for induction and maintenance therapy for ulcerative colitis. N Engl J Med 2005;353:2462-76.

28. Toruner M, Loftus EV, Jr., Harmsen WS, et al. Risk factors for opportunistic infections in patients with inflammatory bowel disease. Gastroenterology 2008;134:929-36. 


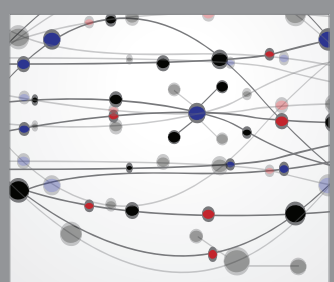

The Scientific World Journal
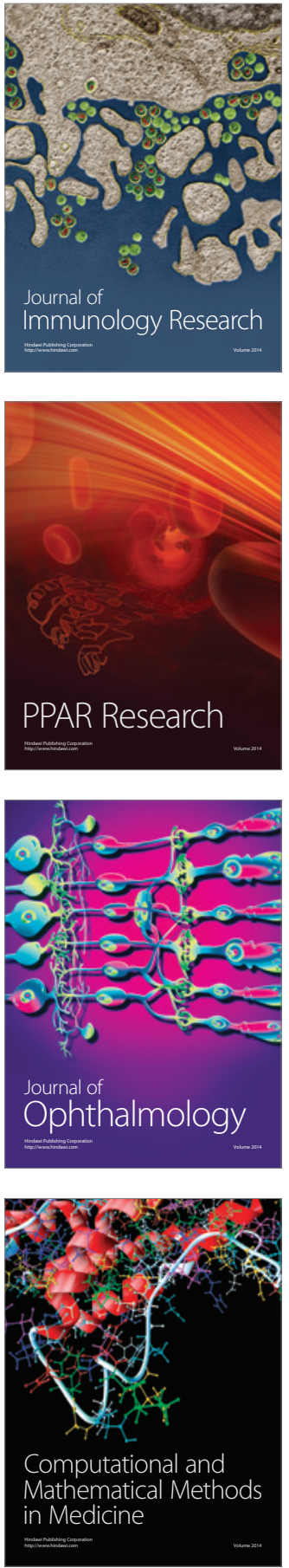

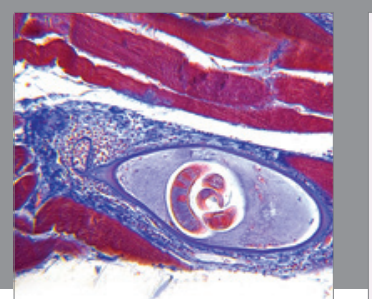

Gastroenterology Research and Practice

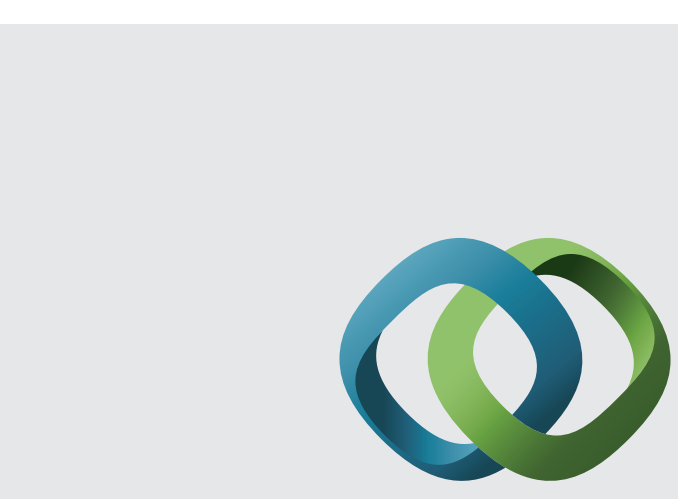

\section{Hindawi}

Submit your manuscripts at

http://www.hindawi.com
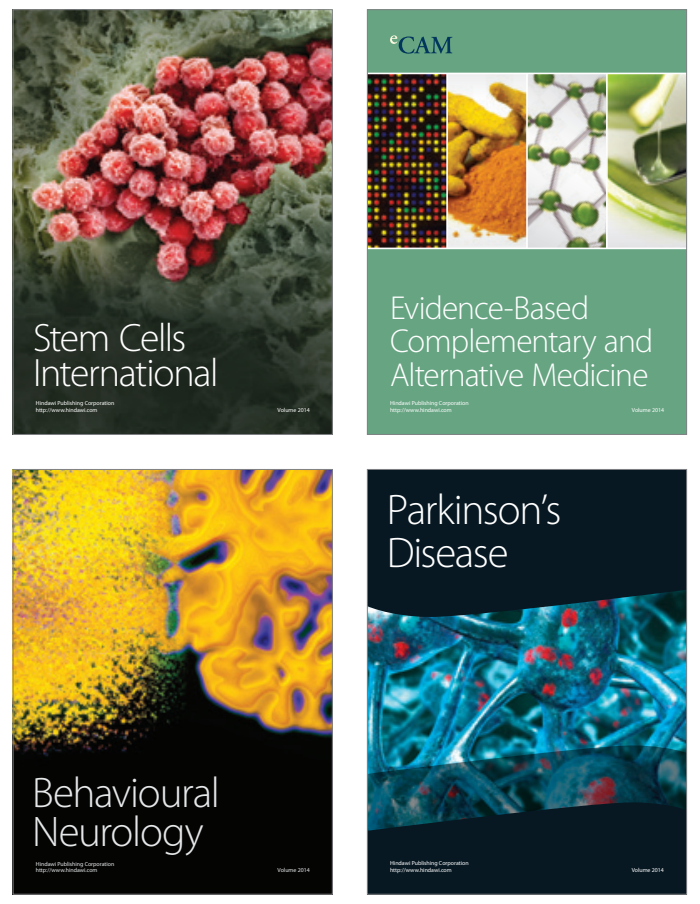
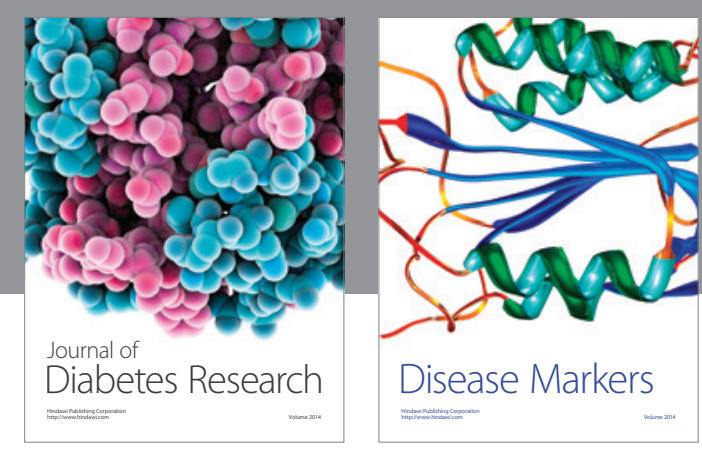

Disease Markers
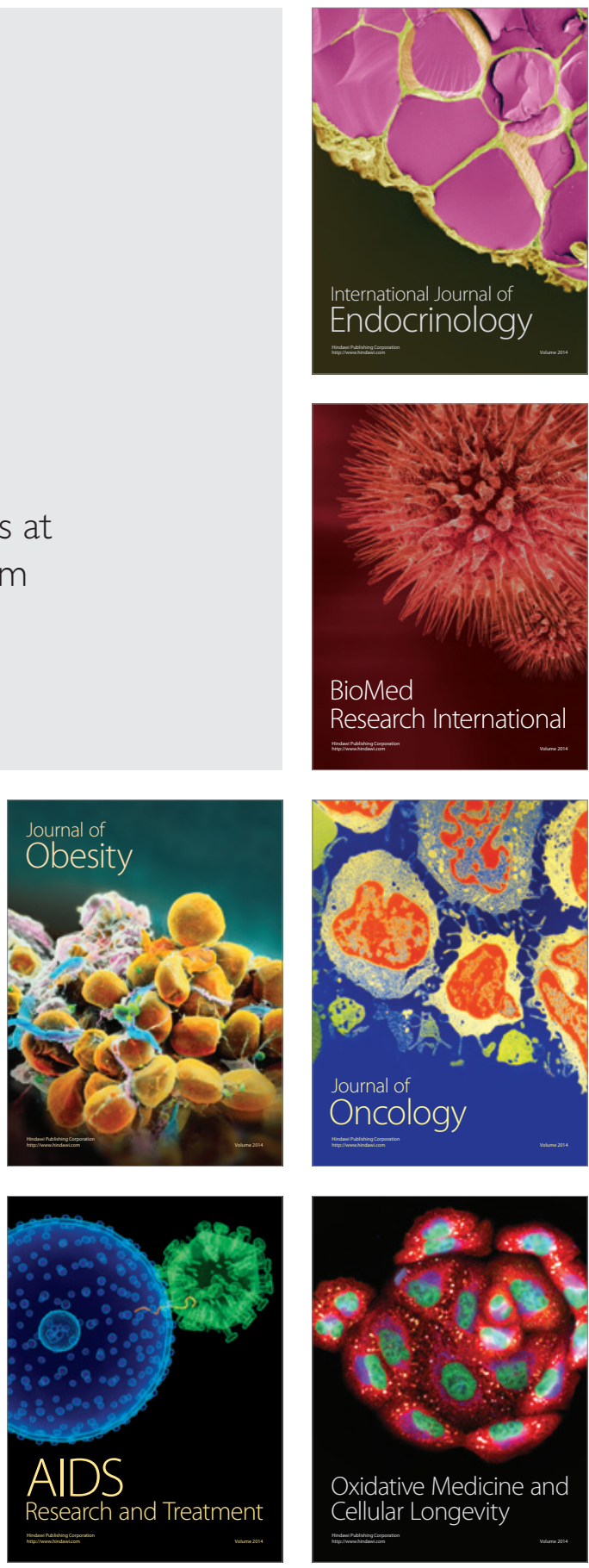